\title{
CFD Prediction of Hydrodynamics in High-Pressure Trickle Bed Reactor
}

\author{
Arnab ATTA, Shantanu RoY and K. D. P. NigAM \\ Department of Chemical Engineering, Indian Institute of Technology \\ Delhi, Hauz Khas, New Delhi 110 016, India
}

Keywords: Trickle Bed, CFD, Two-Phase Flow, High Pressure, Relative Permeability

\begin{abstract}
Most commercial trickle-bed reactors (TBRs) normally operate at high pressures. This study presents the initial development of a comprehensive CFD based model to predict pressure drop and liquid saturation in TBRs under high pressure. A two-phase Eulerian CFD model envisaging the flow domain as porous region for evaluating these hydrodynamic parameters even for high pressure operations, has been proposed. Evaluation of model predictions have been carried out with reported experimental data, collected under varied set of operating conditions. All the comparisons lead to the favorable implementation this less computationally intensive, yet first-principle based CFD model to forecast the two-phase pressure drop and liquid saturation for TBRs operating at high pressures.
\end{abstract}

\section{Introduction}

Trickle-bed reactors (TBRs) are packed beds of catalyst with cocurrent flow of gas and liquid reactants. They represent an important class of multiphase reactors for carrying out gas-liquid reactions in the presence of heterogeneous solid catalysts. There are many applications of trickle-bed reactors in the petroleum industry, as well as in the chemical process industry. The most extensive and popular uses of these reactors are in the field of petroleum refining industry, more specifically in hydroprocessing of petroleum feedstocks and upgradation of petroleum fractions. In recent decades, requirements of stringent environmental regulations have necessitated the so-called "deep processing." For example, in "deep hydrodesulfurization" of diesel cuts for removal of ppm levels of refractory sulfur compounds, TBRs are the contactors of choice. In this way, they are also playing a dominant role in containment of environmental pollution.

Pressure drop and liquid saturation are the principal important hydrodynamic parameters in the operation of TBRs, as the frictional pressure drop is a measure of gas-liquid and liquid-solid mass transfer (Gianetto et al., 1978) and liquid saturation is related to other important parameters, namely, pressure gradient, gas-liquid interfacial area, the mean residence time of the liquid phase, catalyst loading per unit volume, axial dispersion coefficient, and mass-transfer and heat-transfer coefficients (Attou, 1999; Narasimhan et al., 2002). There are numerous models available for predicting these hydrodynamic parameters in the open literature which can be broadly

Received on July 9, 2008; accepted on January 4, 2009. Correspondence concerning this article should be addressed to A. Atta (E-mail address: roys@ chemical.iitd.ac.in).

Presented at ISCRE 20 in Kyoto, September, 2008. classified into two different categories on the basis of empirical approach and theoretical or semi-empirical approach (for details, reader is referred to Atta et al. (2007a) and the references listed therein). Most importantly, in most of these cited references, the studies have been limited to the atmospheric pressure condition. Surprisingly, there is rather scarce amount of research dealing with investigation of pressure drop and liquid saturation in TBRs operating at high pressures (Wammes and Westerterp, 1990; Wammes et al., 1990, 1991; Larachi et al., 1991; Al-Dahhan and Dudukovic, 1994; Nemec et al., 2001; Narsimhan et al., 2002; Nemec, 2003; Nemec and Levec, 2005). These studies led to the conclusion that the hydrodynamic parameters are mostly affected by the gas density, and the correlations developed from atmospheric data were unable to provide satisfactory prediction over the entire range of operating pressure for an industrial trickle-bed reactor (Wammes and Westerterp, 1990; Al-Dahhan and Dudukovic, 1994). It had also been pointed out that the flow regime boundary (from trickle flow to pulsing regime) shifts towards higher superficial liquid velocities when the reactor operating pressure was increased (Wammes et al., 1990). The phenomenological explanation of this shift was provided based on the fact that with increased operating pressure due to higher gas density, dynamic liquid saturation decreases which in turn reduces the mean liquid film thickness over the catalyst packing. Subsequently the liquid films become too thin to collapse any more to initiate the pulses, which is a necessary condition for the flow transition to occur. Therefore, higher liquid throughput compared to the atmospheric conditions is essential to generate sufficient saturation to introduce the pulses. However, considerable debate still persists on the exact nature of approach to deal with the complexity and multiplicity involved 
hydrodynamics of high-pressure TBR.

One possible argument for modeling TBR behavior under high pressure may be to consider/implement the augmented gas-liquid interactions due to higher operating pressure while solving for flow governing equations. Another approach may be to develop a flow model based on physical quantitative description of two-phase flow based on coherent hydrodynamic assumptions along with correctly measured experimental data even at high pressures and fluid velocities (Nemec, 2003).

In addition to this, despite increasing computational power and development of computational fluid dynamics (CFD) and its extensive applications to the modeling of multiphase flow in TBR (Jiang et al., 2002a, 2002b; Gunjal et al., 2003, 2005; Atta et al., 2007a, 2007b), to the best of our knowledge, a CFD based model to predict the hydrodynamics of two-phase flow in TBR operating at high pressure is yet to be reported. Therefore, with the current interest in numerical prediction of hydrodynamics of trickle-bed reactors operating at high pressures, in this article we propose to employ our previously established CFD model (Atta et al., 2007a) for this purpose. The CFD predictions were validated with the independent experimental datasets, notably using the hydrodynamics studies reported by Al-Dahhan and Dudukovic (1994).

\section{Model Development and Numerical Modeling}

In this research work, we extend the use of our previously established CFD model (Atta et al., 2007a) for the estimation of pressure drop and liquid saturation in trickle-bed reactors operating at high pressures. A twophase Eulerian model based on the porous media concept, describing the flow domain as porous region has been presented to forecast the hydrodynamics of twophase flow in trickle-bed reactors (TBRs) under cold-flow conditions. The platform used was FLUENT 6.2 software (ANSYS Inc.).

\subsection{Model equations}

The model equations describing the gas and liquid two-phase flow through the packed bed are based on phasic volume fraction concept, wherein the solid phase is described as an equivalent porous media with two-phase gas-liquid flow flowing through the porous media. The volume-averaged equations for each flowing phase can be written as:

Continuity equation

$$
\frac{\partial\left(\varepsilon_{\alpha} \rho_{\alpha}\right)}{\partial t}+\nabla \cdot\left(\varepsilon_{\alpha} \rho_{\alpha} U_{\alpha}\right)=0 ; \quad \alpha=g, l
$$

Momentum balance equation

$$
\begin{aligned}
& \frac{\partial\left(\varepsilon_{\alpha} \rho_{\alpha} U_{\alpha}\right)}{\partial t}+\nabla \cdot\left(\varepsilon_{\alpha} \rho_{\alpha} U_{\alpha} U_{\alpha}\right) \\
& =-\varepsilon_{\alpha}\left(\nabla p_{\alpha}-\rho_{\alpha} g\right)+\nabla \cdot \varepsilon_{\alpha}\left(\tau_{\alpha}+R_{\alpha}\right)+F_{\alpha}
\end{aligned}
$$

where $F_{\alpha}=$ total drag force per unit of bed volume exerted by the phase $\alpha ; U_{\alpha}$ is the $\alpha$-phase interstitial velocity, $\tau_{\alpha}$ and $R_{\alpha}$ are, respectively, the volume averaged viscous stress tensor and the turbulence stress tensor of phase $\alpha$. Inter-phase coupling terms in Eq. (2) are based on relative permeability concept developed by Sáez and Carbonell (1985), which is mathematically represented as:

$$
\frac{F_{\alpha}}{\varepsilon_{\alpha}}=\frac{1}{k_{\alpha}}\left[A \frac{\mathrm{Re}_{\alpha}}{\mathrm{Ga}_{\alpha}}+B \frac{\mathrm{Re}_{\alpha}^{2}}{\mathrm{Ga}_{\alpha}}\right] \rho_{\alpha} g
$$

where $A$ and $B$ in the Eq. (3) are the Ergun equation coefficients for single-phase flow in the packed bed (Ergun, 1952). The Reynolds and Galileo numbers are defined as:

$$
\begin{aligned}
& R e_{\alpha}=\frac{\rho_{\alpha} u_{\alpha} d_{\mathrm{e}}}{\mu_{\alpha}(1-\varepsilon)} \\
& G a_{\alpha}=\frac{\rho_{\alpha}^{2} g d_{\mathrm{e}}^{3} \varepsilon^{3}}{\mu_{\alpha}^{2}(1-\varepsilon)^{3}}
\end{aligned}
$$

where

$$
d_{\mathrm{e}}=\frac{6 V_{\mathrm{p}}}{A_{\mathrm{p}}}
$$

Since, the Ergun equation has been modified by relative permeability parameter which has been incorporated to accommodate the presence of a second phase; essentially it will be a function of phase saturation or holdup of that corresponding phase. To determine the dependence of the relative permeability on the saturation for each phase Sáez and Carbonell (1985) analyzed different data sets for liquid saturation and pressure drop over a wide range of Reynolds and Galileo numbers in packed beds available in the literature till that time. Recently, Nemec and Levec (2005) have presented a modified set of correlations for evaluating the relative permeabilities $\left(k_{\alpha}\right)$ from a wide range of commercially relevant operating conditions (including pressures up to 50 bar) as well as for a variety of packing (both in terms of size and shape). In this present effort, we have adopted the relative permeability correlation sets from Nemec (2003) for the closure, which states that:

$$
\begin{aligned}
& k_{1}=\delta_{1}^{2.9}\left(\delta_{1} \geq 0.3\right), \quad k_{\mathrm{g}}=0.40 S_{\mathrm{g}}^{3.6}\left(S_{\mathrm{g}} \leq 0.64\right), \\
& k_{1}=0.40 \delta_{1}^{2.1}\left(\delta_{1}<0.3\right), k_{\mathrm{g}}=S_{\mathrm{g}}^{5.5}\left(S_{\mathrm{g}}>0.64\right)
\end{aligned}
$$

\subsection{Numerical solution strategy}

Considering a two-dimensional axisymmetric domain, the above set of model equations was solved using commercial software FLUENT 6.2 (ANSYS. Inc.) defining the solution domain as porous. The bed dimensions were chosen according to the packed bed characteristics prescribed by Al-Dahhan and Dudukovic (1994).

In order to solve the governing equations, the assumptions made in this model are:

- There is no inter-phase mass transfer; 


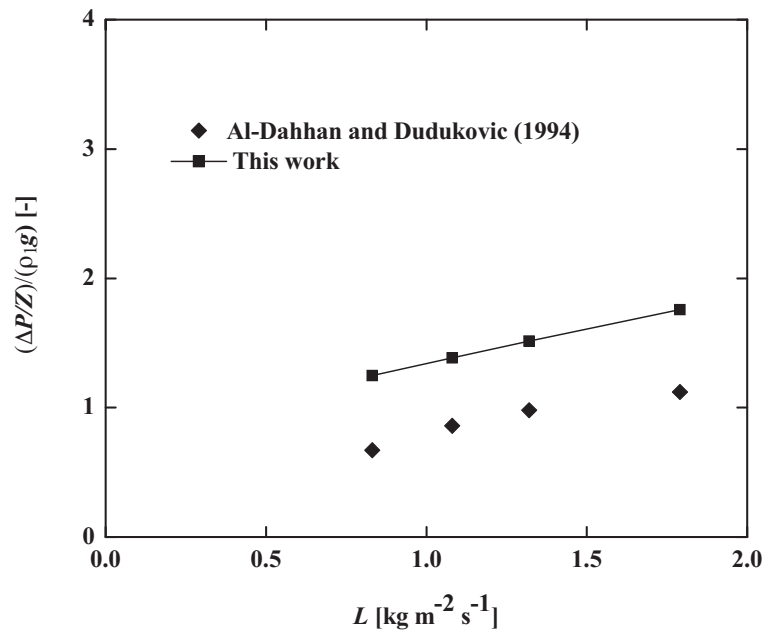

(a)

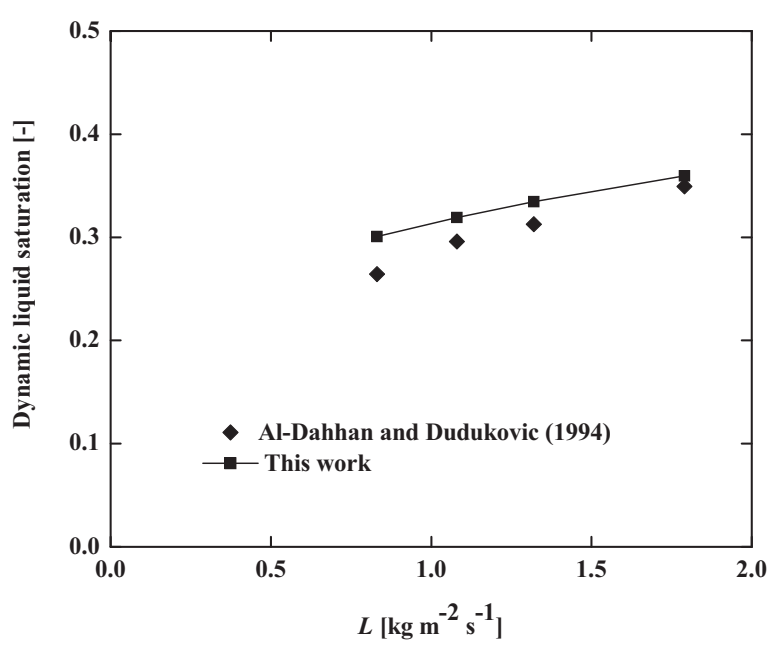

(b)

Fig. 1 Comparative study of (a) pressure drop and (b) liquid saturation with literature data; system: hexanenitrogen; porous extrudate of $0.5 \% \mathrm{Pd}$ on alumina; $P=0.31 \mathrm{MPa}$ and $u_{g}=0.0873 \mathrm{~m} \mathrm{~s}^{-1}$

- The density of the fluids remain unchanged inside the bed;

- The contribution of the turbulent stress terms to overall momentum balance Eq. (2) is not significant. This assumption has also been used by other authors (e.g., Jiang et al., 2002a).

The gas phase was treated as primary phase and liquid phase was considered as secondary phase. At the inlet, flat velocity profile for gas and liquid phases was assumed and implemented. No slip boundary condition was set for all the impermeable reactor walls. At the bottom of the column, an outlet boundary condition was specified. Some preliminary numerical experiments were carried out to identify the required number of computational

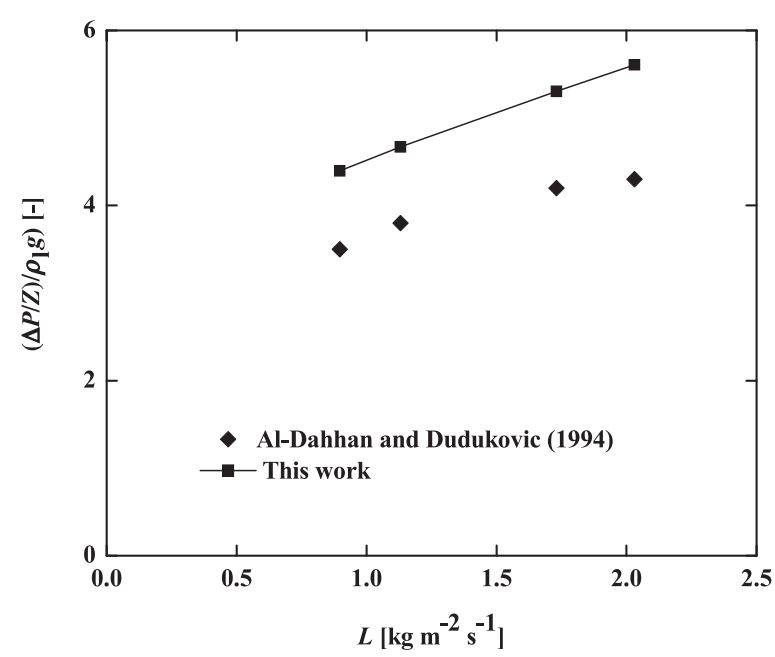

(a)

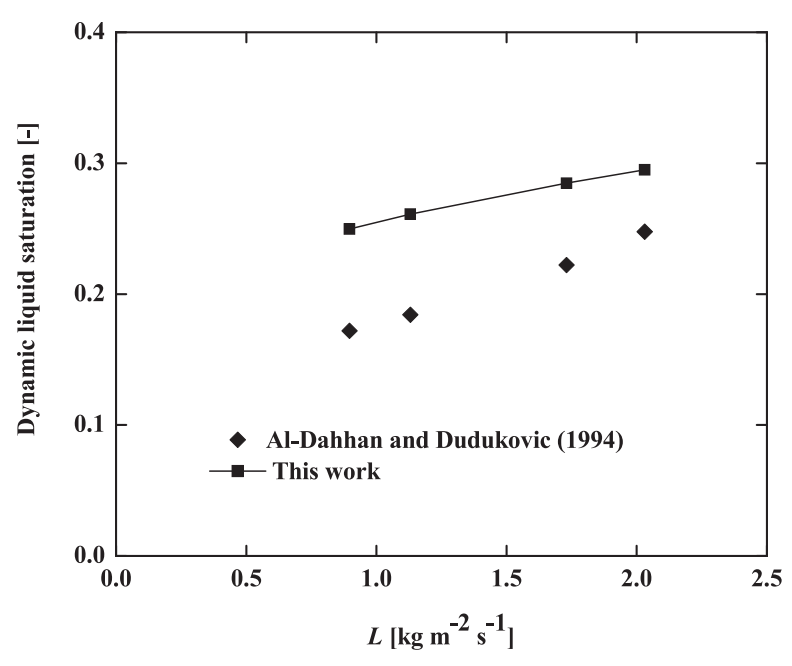

(b)

Fig. 2 Comparative study of (a) pressure drop and (b) liquid saturation with literature data; system: hexanenitrogen; porous extrudate of $0.5 \% \mathrm{Pd}$ on alumina; $P=3.55 \mathrm{MPa}$ and $u_{g}=0.0875 \mathrm{~m} \mathrm{~s}^{-1}$

cells to obtain grid independent results. It was also ensured with the preliminary numerical experiments to have results independent of the discretization scheme.

\section{Results and Discussion}

Several numerical simulations were carried out and the simulated results were validated against the published experimental data of pressure drop and liquid saturation from an independent source (Al-Dahhan and Dudukovic, 1994). The details of the operating conditions for the experimental datasets (adopted from Al-Dahhan and Dudukovic, 1994) are shown in Table 1.

Figures 1, 2 and 3 show the comparison of simulated results with the experimental data of Al-Dahhan 
Table 1 Details of operation conditions used for simulations

\begin{tabular}{|c|c|c|c|c|c|c|}
\hline \multirow[t]{2}{*}{ Source } & \multirow[t]{2}{*}{ Operating } & \multicolumn{2}{|l|}{ System } & \multicolumn{3}{|l|}{ Packing } \\
\hline & & & & & Size $[\mathrm{mm}]$ & Bed porosity \\
\hline \multirow[t]{3}{*}{$\begin{array}{l}\text { Al-Dahhan and } \\
\text { Dudukovic (1994) }\end{array}$} & \multirow[t]{3}{*}{$0.3-5.0$} & \multirow[t]{3}{*}{$\begin{array}{l}\text { Water, } \\
\text { Hexane }\end{array}$} & \multirow[t]{3}{*}{$\begin{array}{l}\text { Nitrogen, } \\
\text { Helium }\end{array}$} & $\begin{array}{l}0.5 \% \mathrm{Pd} / \text { alumina } \\
\text { (extrudate), porous }\end{array}$ & $\left(d_{\mathrm{p}}\right)_{\mathrm{eq}}=1.99$ & 0.355 \\
\hline & & & & $\begin{array}{l}\text { Glass beads (sphere), } \\
\text { nonporous }\end{array}$ & $d_{\mathrm{p}}=1.14$ & 0.392 \\
\hline & & & & $\begin{array}{l}\text { Silica shell (sphere), } \\
\text { porous }\end{array}$ & $d_{\mathrm{p}}=1.52$ & 0.412 \\
\hline
\end{tabular}

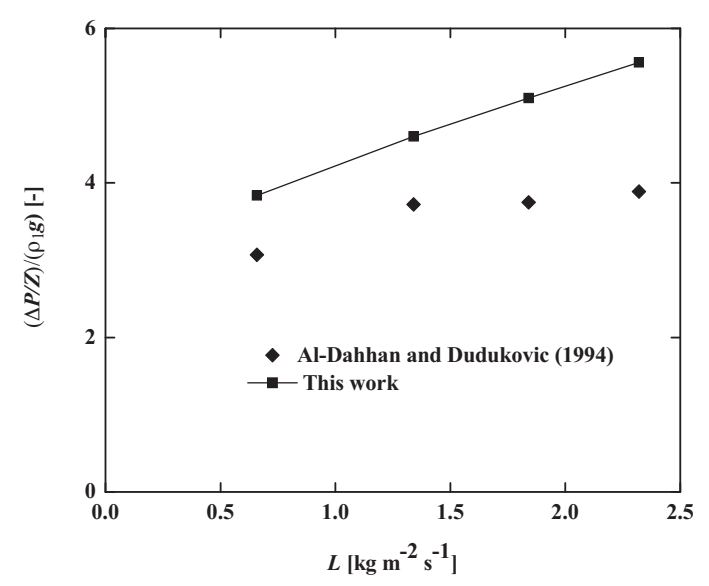

(a)

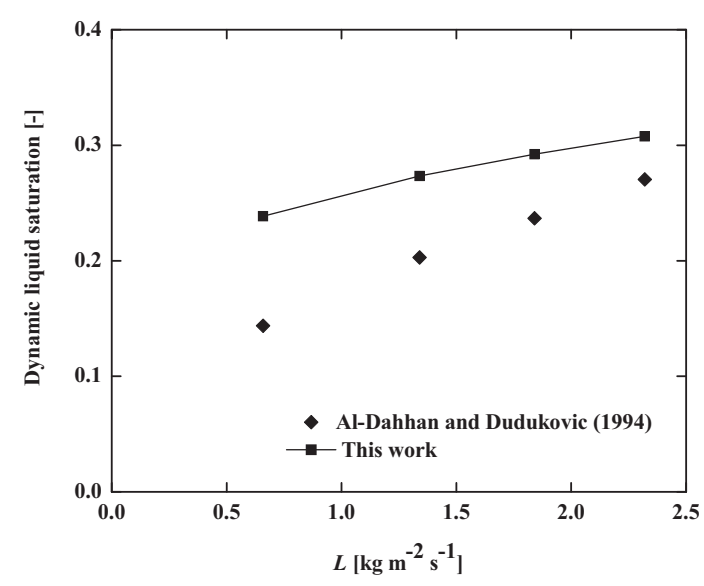

(b)

Fig. 3 Comparative study of (a) pressure drop and (b) liquid saturation with literature data; system: hexanenitrogen; porous extrudate of $0.5 \% \mathrm{Pd}$ on alumina; $P=4.93 \mathrm{MPa}$ and $u_{g}=0.072 \mathrm{~m} \mathrm{~s}^{-1}$

and Dudukovic (1994) for observed pressure drop per unit length and liquid saturation. For the given system of hexane-nitrogen with $0.5 \% \mathrm{Pd} /$ alumina porous extrudate catalyst, Figures 1 and 2 represent the comparative studies of effect of reactor pressure for two different operating pressures $(0.31 \mathrm{MPa}$ and $3.55 \mathrm{MPa})$ on pressure drop and liquid saturation with literature data for a con-

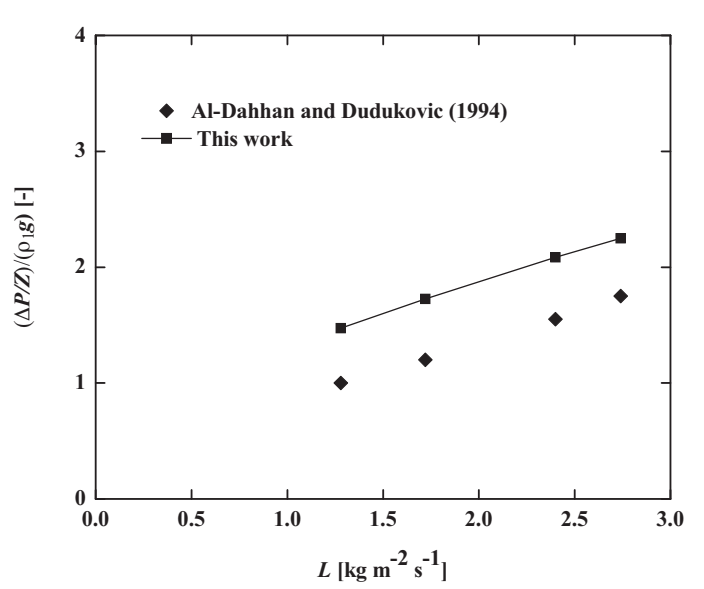

(a)

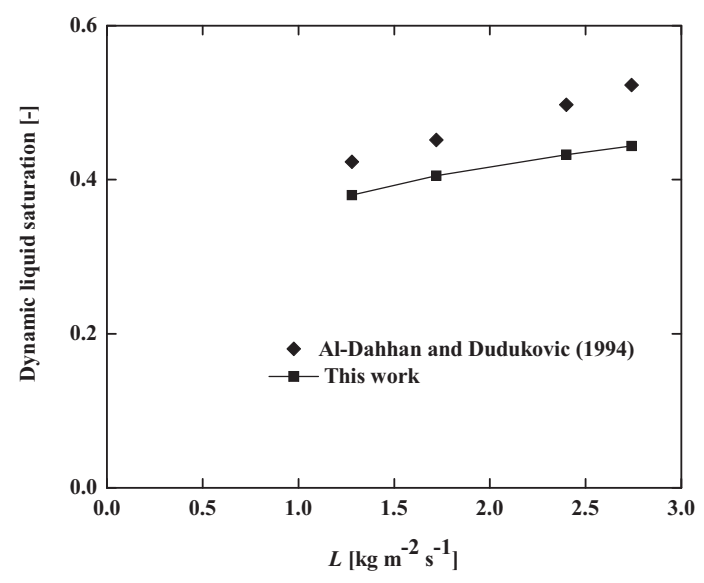

(b)

Fig. 4 Comparative study of (a) pressure drop and (b) liquid saturation with literature data; system: hexanenitrogen; nonporous glass bead; $P=0.31 \mathrm{MPa}$ and $u_{g}=0.042 \mathrm{~m} \mathrm{~s}^{-1}$

stant gas velocity of about $8.75 \mathrm{~cm} \mathrm{~s}^{-1}$. It can clearly be observed that for a particular gas velocity, with the increase in operating pressure, frictional pressure drop per unit length increases whereas corresponding liquid saturation decreases. Figure 3 is an example of predicting hydrodynamics of high-pressure TBR at a limiting condition with high pressure (of about 50 bar) and high su- 


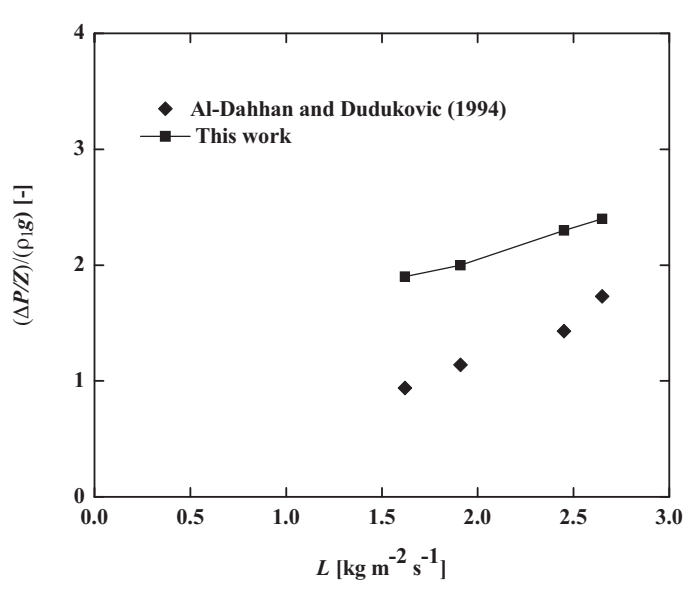

(a)

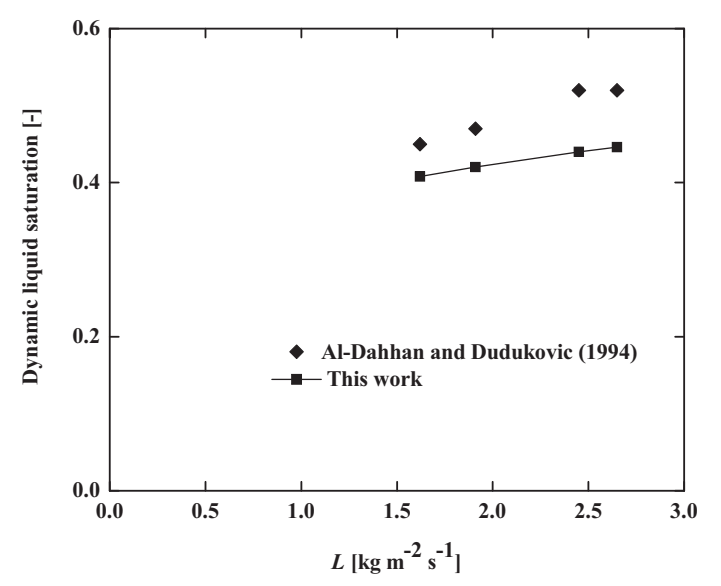

(b)

Fig. 5 Comparative study of (a) pressure drop and (b) liquid saturation with literature data; system: hexanehelium; nonporous glass bead; $P=2.13 \mathrm{MPa}$ and $u_{g}=0.0415 \mathrm{~m} \mathrm{~s}^{-1}$

perficial gas velocity. All these predicted results are in reasonable agreement with the experimental data (both for dimensionless pressure drop and liquid saturation).

Figures 4 and 5 represent the comparison of this CFD model prediction with experimental data from AlDahhan and Dudukovic (1994) to study the effect of different gas densities for a given system of hexane and nitrogen/helium with nonporous spherical glass beads as catalyst particles. It can be seen from these figures (Figures 4 and 5) that for a system with nitrogen as gas phase and with $0.31 \mathrm{MPa}$ operating pressure exhibits almost same pressure drop and liquid saturation as in the case for a system with helium as gas phase and with $2.13 \mathrm{MPa}$ operating pressure. This interesting result is also evident from the numerical predictions of this work. The reason behind this observation is that the density of helium at $2.13 \mathrm{MPa}\left(\sim 3.44 \mathrm{~kg} \mathrm{~m}^{-3}\right)$ is almost equals to that of nitrogen at $0.31 \mathrm{MPa}$ pressure $\left(\sim 3.51 \mathrm{~kg} \mathrm{~m}^{-3}\right)$. Therefore, both the gas phases behave similar at those corresponding

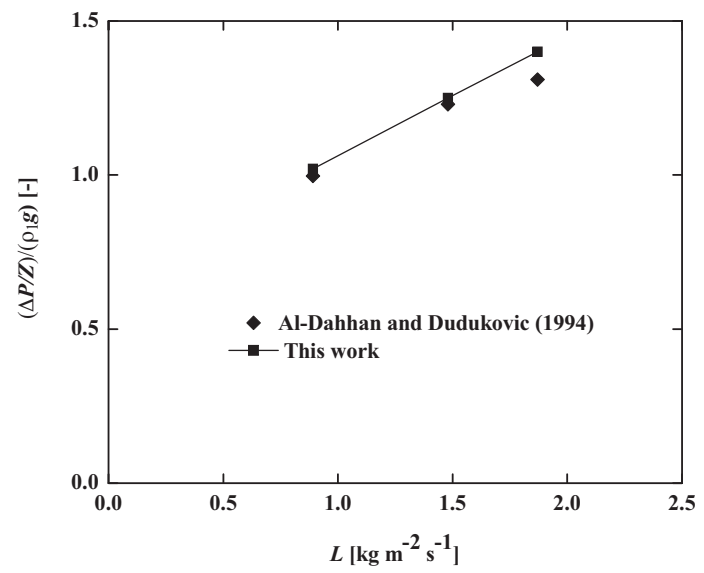

(a)

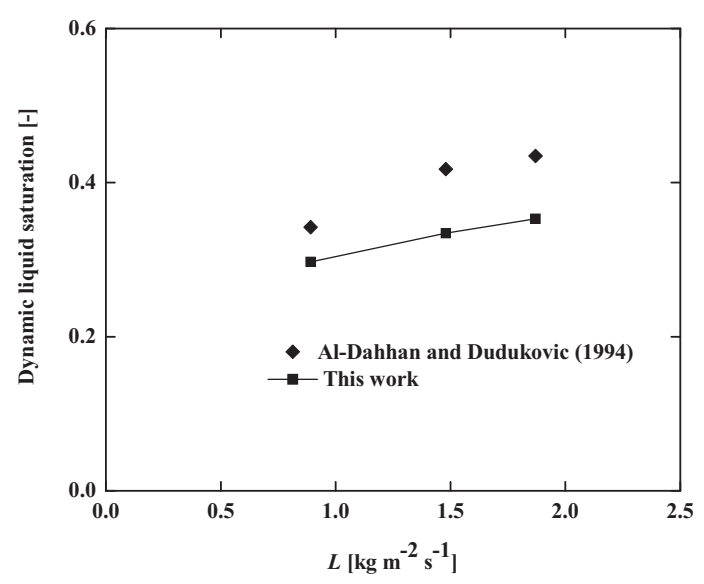

(b)

Fig. 6 Comparative study of (a) pressure drop and (b) liquid saturation with literature data; system: hexanenitrogen; porous silica shell; $P=0.31 \mathrm{MPa}$ and $u_{g}=0.085 \mathrm{~m} \mathrm{~s}^{-1}$

operating pressures for the same flow rate (in this case $\approx$ $4.2 \mathrm{~cm} \mathrm{~s}^{-1}$ ). Figure 6 is an example of comparative study of pressure drop as well as liquid saturation with literature data for another different set of bed packing (porous spherical silica shell). With the present effort, it may be asserted that this first ever CFD model to forecast hydrodynamics of high-pressure TBR functions arguably well in predicting a wide range of operating condition including different particle shape and size of the packing.

\section{Conclusions}

A less computationally intensive, yet first-principle based CFD model has been presented in this work using the porous media concept to forecast the pressure drop and liquid saturation of the TBRs operating at high pressure. While simulating for high pressure condition, we have applied the correlations of relative permeabilty factors which mainly stem from the research of Sáez and 
Carbonell (1985) and later modified by Nemec (2003). The developed model is comparatively flexible unlike the traditional CFD approach, i.e. three-phase Eulerian simulations for different particle size effect incorporation without much complexity. This CFD model can productively be implemented for high pressure operation (most of the commercial TBRs operate) which is cumbersome to account for three-phase Eulerian simulation. It can be concluded that our model functions in a satisfactory manner in predicting the experimental data in most cases. In future, this model can be tested with the results from a real trickle-bed reactor for further investigations and robustness. We will also be exploring the model's predictability to more independent experimental data sets in order to ascertain its versatility.

As high pressure operation processes in TBRs are very frequently encountered in petroleum refining industry which is one of the most critical and biggest industry in the globe, any optimistic contribution towards its design via modeling of different parameters will not only lead to technology development thus resulting in substantial savings, but will also help to maintain a cleaner and greener environment.

\section{Acknowledgments}

Arnab Atta is grateful to the All India Council for Technical Education (AICTE), India, for providing National Doctoral Fellowship. Authors also thankfully acknowledge the help of Prof. Janez Levec, University of Ljubljana, Slovenia for providing the Doctoral Thesis of Dr. Damjan Nemec.

\begin{tabular}{|c|c|c|}
\hline \multicolumn{2}{|c|}{ Nomenclature } & \multirow[b]{2}{*}{ Ergun constant of viscous term $\quad[-]$} \\
\hline$A$ & $=$ & \\
\hline$A_{\mathrm{p}}$ & $=$ & particle surface area \\
\hline$B$ & $=$ & Ergun constant of inertial term \\
\hline$d_{\mathrm{e}}$ & $=$ & equivalent particle diameter $\left(=6 V_{\mathrm{p}} / A_{\mathrm{p}}\right)$ \\
\hline$d_{\mathrm{p}}$ & $=$ & particle diameter \\
\hline$E o^{*}$ & $=$ & modified Eötvos number $\left(=\rho_{1} g d_{\mathrm{p}}^{2} \varepsilon^{2} /\left[\sigma_{1}(1-\varepsilon)^{2}\right]\right)$ \\
\hline$F_{\alpha}$ & $=$ & drag force per unit volume $\quad\left[\mathrm{kg} \mathrm{m}^{-2} \mathrm{~s}^{[-2}\right]$ \\
\hline$G a_{\alpha}$ & $=$ & Galileo number $\left(=\rho_{\alpha}^{2} g d_{\mathrm{e}}^{3} \varepsilon^{3} /\left[\mu_{\alpha}^{2}(1-\varepsilon)^{3}\right]\right)$ \\
\hline$g$ & $=$ & gravitational acceleration $\quad\left[\mathrm{m} \mathrm{s}^{-2}\right]$ \\
\hline$k_{\alpha}$ & $=$ & relative permeability of $\alpha$ phase \\
\hline$L$ & $=$ & superficial liquid mass velocity \\
\hline$p$ & $=$ & Reactor pressure \\
\hline$R e_{\alpha}$ & $=$ & Reynolds number $\left(=\rho_{\alpha} \varepsilon_{\alpha} u_{\alpha} d_{\mathrm{e}} /\left[\mu_{\alpha}(1-\varepsilon)\right]\right)$ \\
\hline$S_{\alpha}$ & $=$ & saturation of $\alpha$ phase \\
\hline$u$ & $=$ & superficial velocity \\
\hline$V_{\mathrm{p}}$ & $=$ & particle volume \\
\hline Z & $=$ & length of the reactor \\
\hline$\delta_{1}$ & $=$ & reduced saturation $\left(=\left(\varepsilon_{1}-\varepsilon_{1}^{0}\right) /\left(\varepsilon-\varepsilon_{1}^{0}\right)\right)$ \\
\hline$\varepsilon_{1}^{0}$ & $=$ & static liquid hold up \\
\hline$\varepsilon$ & $=$ & bed voidage \\
\hline$\varepsilon_{\alpha}$ & $=$ & hold-up of $\alpha$ phase \\
\hline$\mu$ & $=$ & viscosity \\
\hline$\rho_{\alpha}$ & $=$ & density of $\alpha$ th phase \\
\hline$\sigma$ & $=$ & surface tension \\
\hline
\end{tabular}

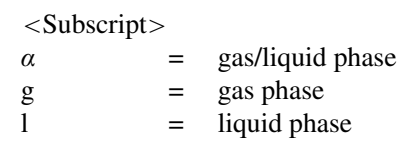

\section{Literature Cited}

Al-Dahhan, M. H. and M. P. Dudukovic; "Pressure Drop and Liquid Holdup in High-Pressure Trickle-Bed Reactors," Chem. Eng. Sci., 49, 5681-5698 (1994)

Atta, A., S. Roy and K. D. P. Nigam; "Prediction of Pressure Drop and Liquid Holdup in Trickle Bed Reactor Using Relative Permeability Concept in CFD," Chem. Eng. Sci., 62, 5870-5879 (2007a)

Atta, A., S. Roy and K. D. P. Nigam; "Investigation of Liquid Maldistribution in Trickle-Bed Reactors Using Porous Media Concept in CFD," Chem. Eng. Sci., 62, 7033-7044 (2007b)

Attou, A.; "Hydrodynamics in a Pressurized Cocurrent Gas-Liquid Trickle-Bed Reactor: A Physical Model," Chem. Eng. Technol., 22, 221-230 (1999)

Ergun, S.; "Fluid Flow through Packed Columns," Chem. Eng. Prog., 48, 89-94 (1952)

Gianetto, A., G. Baldi, V. Specchia and S. Sicardi; "Hydrodynamics and Solid-Liquid Contacting Effectiveness in Trickle-Bed Reactors," AIChE J., 24, 1087-1104 (1978)

Gunjal, P. R., V. V. Ranade and R. V. Chaudhari; "Liquid Distribution and RTD in Trickle Bed Reactors: Experiments and CFD Simulations," Can. J. Chem. Eng., 81, 821-830 (2003)

Gunjal, P. R., M. N. Kashid, V. V. Ranade and R. V. Chaudhari; "Hydrodynamics of Trickle-Bed Reactors: Experiments and CFD Modeling," Ind. Eng. Chem. Res., 44, 6278-6294 (2005)

Jiang, Y., M. R. Khadilkar, M. H. Al-Dahhan and M. P. Dudukovic; "CFD of Multiphase Flow in Packed-Bed Reactors: I. $k$-Fluid Modeling Issues," AIChE J., 48, 701-715 (2002a)

Jiang, Y., M. R. Khadilkar, M. H. Al-Dahhan and M. P. Dudukovic; "CFD of Multiphase Flow in Packed-Bed Reactors: II. Results and Applications," AIChE J., 48, 716-730 (2002b)

Larachi, F., A. Laurent, N. Midoux and G. Wild; "Experimental Study of a Trickle Bed Reactor Operating at High Pressure: Two-Phase Pressure Drop and Liquid Saturation," Chem. Eng. Sci., 46, 12331246 (1991)

Narasimhan, C. S. L., R. P. Verma, A. Kundu and K. D. P. Nigam; "Modeling Hydrodynamics of Trickle-Bed Reactors at High Pressure," AIChE J., 48, 2459-2474 (2002)

Nemec, D.; "Pressure Drop and Liquid Holdup in Packed Beds with Cocurrent Two-Phase Flow at High Pressures," Doctoral dissertation, University of Ljubljana, Slovenia (2003)

Nemec, D. and J. Levec; "Flow through Packed Bed Reactors: 2. TwoPhase Concurrent Downflow," Chem. Eng. Sci., 60, 6958-6970 (2005)

Nemec, D., G. Bercic and J. Levec; "The Hydrodynamics of Trickling Flow in Packed Beds Operating at High pressures: The Relative Permeability Concept," Chem. Eng. Sci., 56, 5955-5962 (2001)

Sáez, A. E. and R. G. Carbonell; "Hydrodynamic Parameters for GasLiquid Cocurrent Flow in Packed Beds," AIChE J., 31, 52-62 (1985)

Wammes, W. J. A. and K. R. Westerterp; “The Influence of the Reactor Pressure on the Hydrodynamics in a Cocurrent Gas-Liquid TrickleBed Reactor," Chem. Eng. Sci., 45, 2247-2254 (1990)

Wammes, W. J. A., S. J. Mechielsen and K. R. Westerterp; “The Transition between Trickle Flow and Pulse Flow in a Cocurrent GasLiquid Trickle-Bed Reactor at Elevated Pressures," Chem. Eng. Sci., 45, 3149-3158 (1990)

Wammes, W. J. A., J. Middelkamp, W.-J. Huisman, C. M. De Baas and K. R. Westerterp; "Hydrodynamics in a Cocurrent Gas-Liquid Trickle Bed at Elevated Pressures," AIChE J., 37, 1849-1862 (1991) 